\title{
Effect of Benzalkonium Chloride on Properties of Zinc Oxide Nanoparticles Synthesized through Sol-Gel Technique
}

\author{
Hwda Ghafur Rauf', Madzlan Aziz², Sattar Ibrahim Kareem \\ ${ }^{1}$ Department of Medical Laboratory Sciences, University of Human Development, Sulaymaniyah, Kurdistan Region, Iraq, \\ ${ }^{2}$ Department of Chemistry, University Technology Malaysia, Johor Bahru, Malaysia
}

\section{A B S T R A C T}

In the present study, to synthesize controllable sized metal oxide particles, benzalkonium chloride (BAK) as cationic surfactant was added to zinc oxide $(\mathrm{ZnO})$ nanostructures synthesis at room temperature using sol-gel method. The effect of cationic surfactant BAK concentrations, on the optical properties, size, and morphology of ZnO nanoparticles synthesized through sol-gel method was studied. The characterization of $\mathrm{ZnO}$ nanostructures was occurred using transmission electron microscopy (TEM), X-ray diffraction (XRD), ultraviolet-visible near infrared (UV-Vis) spectrophotometer, Fourier transform infrared spectroscopy (FTIR), and scanning electron microscopy (SEM). ZnO nanostructures shape and size were revealed by SEM and TEM. The hexagonal (wurtzite structure) of ZnO was confirmed by an X-ray diffractogram. The bandgap energy of the prepared $\mathrm{ZnO}$ samples was determined by UV-Vis spectrophotometer. FTIR analyzed the presence of functional groups.

Index Terms: Benzalkonium Chloride, Cationic Surfactants, Sol-Gel Method, Zinc Oxide, Nanostructures

\section{INTRODUCTION}

In an experimentally accessible size range, one of the few oxides that show quantum confinement effects is zinc oxide $(\mathrm{ZnO})$, which is a semiconductor with a wide bandgap of $3.4 \mathrm{eV}$ and a large exciton binding energy of $60 \mathrm{MeV}$ at room temperature. What makes $\mathrm{ZnO}$ favorable is its qualities such as low-temperature process, transparency, and high carrier mobility in addition to cost savings. As well as $\mathrm{ZnO}$ properties, size-dependent optical absorption is also a valuable tool. Therefore, to quantum size $\mathrm{ZnO}$ particles, sol-gel preparation method can be used [1]. In

\begin{tabular}{l|l|} 
Access this article online \\
DOI: 10.21928/uhdjst.v4n1y2020pp41-50 & E-ISSN: 2521-4217 \\
P-ISSN: 2521-4209
\end{tabular}
$\begin{aligned} & \text { Copyright @ 2020 Rauf, et al. This is an open access article distributed } \\
& \text { under the Creative Commons Attribution Non-Commercial No } \\
& \text { Derivatives License 4.0 (CC BY-NC-ND 4.0) }\end{aligned}$

many particle synthetic processes, especially surfactant-free chemical reactions, as particles start to generate, aggregation immediately occurs. This agglomeration for nanostructured materials does cause a problem in the many chemical and pharmaceutical products. The direct mutual attraction between particles through chemical bonding or Van der Waals forces, simply leads to aggregation as represented in conventional studies [2]. Although this agglomeration can be counted onto prevent toxicity of nanoparticles, especially in cosmetic products as $\mathrm{ZnO}$ is widely used such as sunscreen or industrial factories like paint factories [3]. Nanoparticles recently considered to be dangerous, both medically and environmentally [4]. In fact, it has the ability to make the particles very reactive or catalytic because it has a high surface [5]. They are also capable of harming cell membranes in organisms and biological systems [6]. However, if the particles are larger in size, they are unlikely to harm the cell nucleus and other internal cellular components due to the particle agglomeration [7].

Corresponding author's e-mail: Hwda Ghafur Rauf, Department of Medical Laboratory Sciences , University of Human Development, Sulaymaniyah, Kurdistan Region of Iraq. E-mail: hwda.rauf@uhd.edu.iq 
Lung inflammatory and systemic activity can be noticed in experimental animals when they inhaled ultrafine particles unlike an equal mass of larger particles, which may also affect adult human subjects [8].

Due to its bulky bi-tailed structure, which is insoluble, benzalkonium chloride (BAK) particles tend to agglomerate, which caused the increase in the particle size [9].

Several physical and chemical methods could be taken under consideration to synthesize $\mathrm{ZnO}$ nanostructures. Chemical vapor deposition (CVD), metal-organic CVD and molecular beam epitaxy, pyrolysis, vapor-liquid-solid growth, and vapor-solid processes such as thermal reduction, are considered physical methods. At the same time, to have a very large scale production, there are chemical methods that are very simple yet effective such as precipitation, sol-gel, and solvothermal processes. Unlike general methods, these methods do not require high temperatures and sophisticated instruments [10]. In this work, there must be a controllable grain size of particles as a result, to approach that goal, it's better to use the sol-gel method, especially when we adjust the experimental conditions such as concentration, temperature, $\mathrm{pH}$, and reaction time. In addition, this method is simple yet reproducible and does not cost much, not to mention its reliability of stoichiometry control, which makes it a totally suitable process for industrial production of $\mathrm{ZnO}$ [11].

\section{EXPERIMENTAL}

\subsection{Preparation of $\mathrm{ZnO}$ Nanoparticles}

$\mathrm{ZnO}$ nanocrystals were prepared by adding $100.0 \mathrm{~mL}$ of $0.5 \mathrm{~mol} / 1 \mathrm{NaOH}$ solution dropwise slowly into $250.0 \mathrm{~mL}$ of $0.1 \mathrm{~mol} / 1 \mathrm{Zn}(\mathrm{Ac})_{2}$ distilled water using distilled water under vigorous stirring and closed vessel to produce the $\mathrm{Zn}(\mathrm{OH})_{2}$ precipitate, then an appropriate amount of $\mathrm{NH}_{4} \mathrm{HCO}_{3}$ $(0.8 \mathrm{~g})$ powder was added to adjust ph value of the solution. After stirring for $30 \mathrm{~min}$, a semitransparent zinc carbonate hydroxide colloid was obtained. After $30 \mathrm{~min}$, the colloid was centrifuged and dried at $80^{\circ} \mathrm{C}$. Thus, the precursor of a small crystallite of $\mathrm{Zn}_{5}\left(\mathrm{CO}_{3}\right)_{2}(\mathrm{OH})_{6}$ with white color was formed then calcined at $450^{\circ} \mathrm{C}$ for $2 \mathrm{~h}$. The sample was washed by deionized water, and finally, the product was dried at $70^{\circ} \mathrm{C}$ to obtain the white colored sample of $\mathrm{ZnO}$ nanoparticle.

\subsection{Preparations of $\mathrm{ZnO}$ Nanoparticles with $B A K$}

The procedure was repeated as in 2.1 with addition BAK (95\% purity Sigma-Aldrich) $\left(1 \times 10^{-5} \mathrm{M}\right.$ below, $5 \times 10^{-5} \mathrm{M}$ at, $15 \times 10^{-5} \mathrm{M}$ above) critical micelle concentration (CMC), respectively. The $\mathrm{CMC}$ value of $\mathrm{BAK}$ was taken from literature data [12]. Although this time, the precursor was calcined at $550^{\circ} \mathrm{C}$ for $5 \mathrm{~h}$ to obtain the sample, as shown in Fig. 1. Finally, the product was dried at $70^{\circ} \mathrm{C}$ to obtain the white-colored sample of $\mathrm{ZnO}$.

\section{RESULTS AND DISCUSSION}

The CMC value of BAK was taken from literature data and it was $0.04 \mathrm{mM}$ [12].

\subsection{Analysis of Fourier Transformed Infrared (FTIR)}

Fig. $2 \mathrm{a}$ shows the FTIR spectrum of prepared $\mathrm{ZnO}$ nanoparticles without BAK. Furthermore, Fig. 2b-d shows

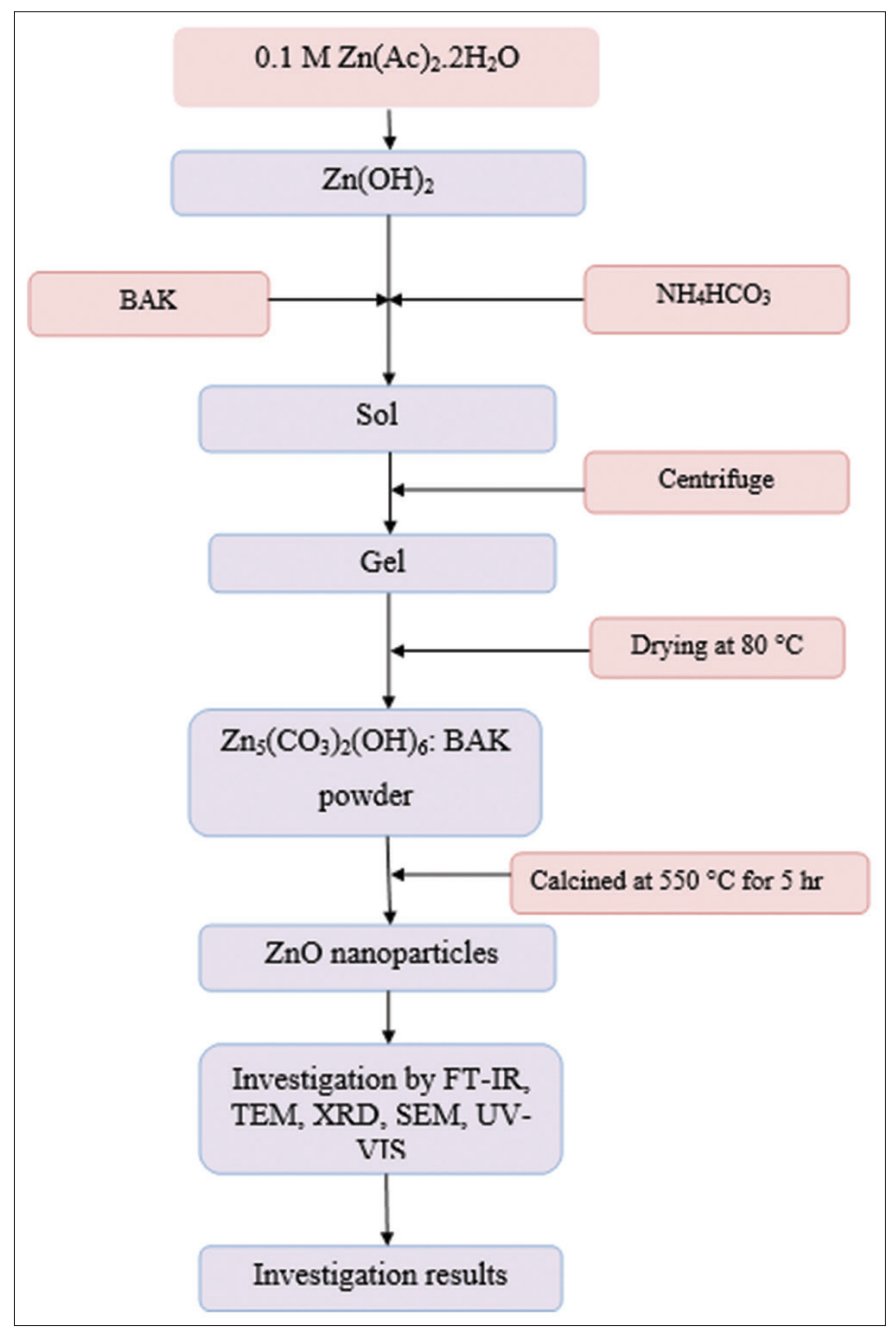

Fig. 1. Preparation of benzalkonium chloride with benzalkonium chloride surfactant. 


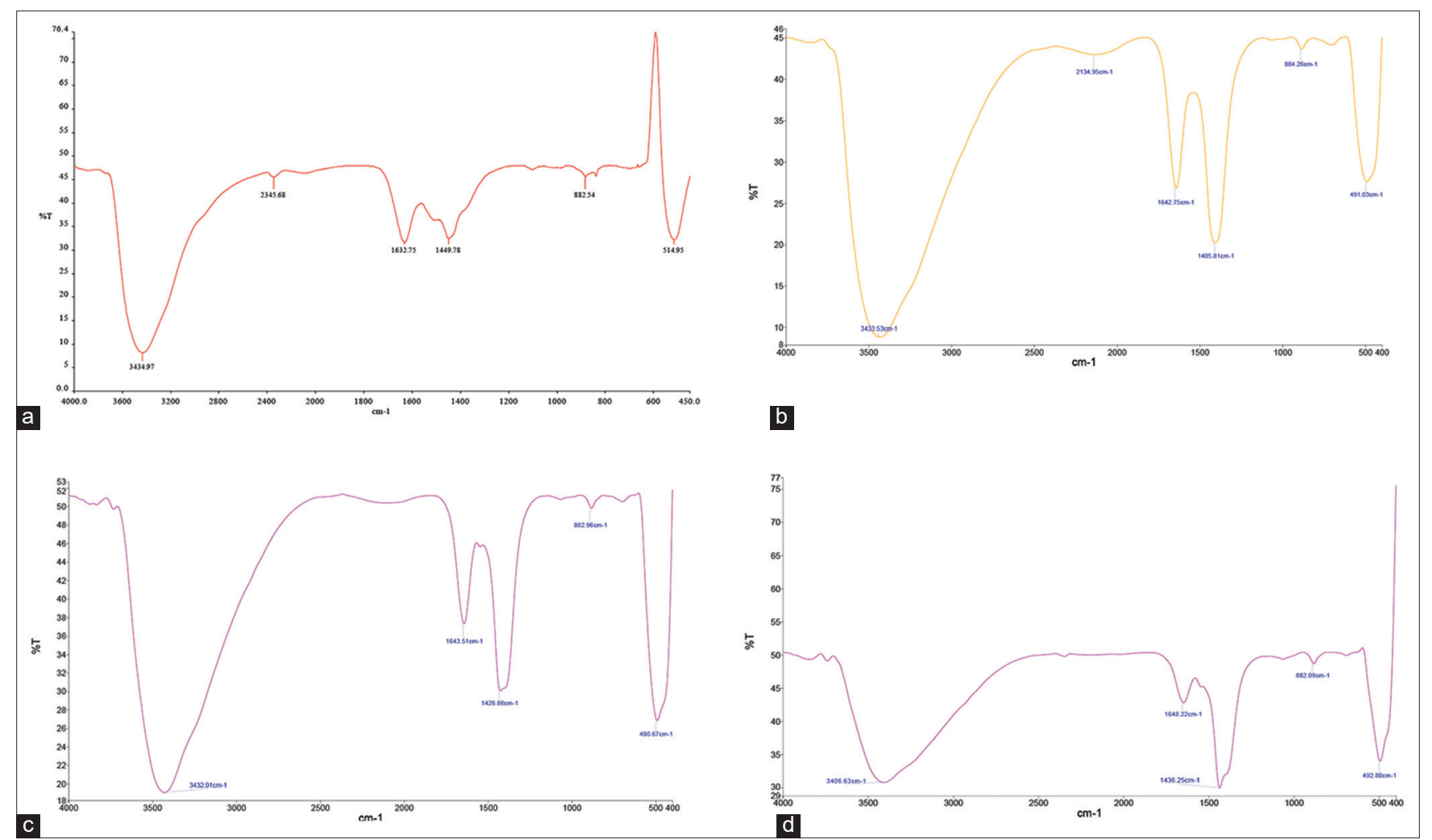

Fig. 2. Combined Fourier transformed infrared spectra of zinc oxide nanoparticles without and with benzalkonium chloride (BAK) surfactant (a) without surfactant, (b) with BAK below critical micelle concentration (CMC), (c) with benzalkonium chloride at CMC, (d) with BAK above CMC.

the FT-IR spectra of prepared $\mathrm{ZnO}$ particles in the presence of BAK (below CMC, at CMC, and after CMC), respectively. The broad absorption band centered above $3000 \mathrm{~cm}^{-1}$ is attributable to the band $\mathrm{O}-\mathrm{H}$ stretching vibrations of water molecules on $\mathrm{ZnO}$, and the band near $1630 \mathrm{~cm}^{-1}$ is assigned to the covalent bond in $\mathrm{H}-\mathrm{O}-\mathrm{H}$ bending vibrations mode which were also presented due to the adsorption of humidity in the air when FT-IR sample disks were prepared in an open air.

The spectrums near $1450 \mathrm{~cm}^{-1}$ indicate the existence of C-O. However, for $\mathrm{ZnO}$ samples with BAK surfactant, the calcination temperature was raised at $550^{\circ} \mathrm{C}$ for $5 \mathrm{~h}$ and is not blue shifted. The difference in the calcination temperatures and the time could explain the difference among the figures.

\subsection{Analysis of Scanning Electron Microscope (SEM)}

The morphology of the prepared $\mathrm{ZnO}$ samples was determined by SEM analysis, as shown in Figs. 3-6. ZnO samples with $\mathrm{BAK}$ that is calcined at $550^{\circ} \mathrm{C}$ for $5 \mathrm{~h}$, do not reveal uniform morphology. The structure of BAK is bulky and bi-tailed which is insoluble; the particles tend to agglomerate, which caused the increase in the particle size [9]. The particle size of $\mathrm{ZnO}$ sample was taken by line intersecting method; the result revealed that the prepared $\mathrm{ZnO}$ sample without BAK in Fig. 3 was in the range of $80-85 \mathrm{~nm}$ which smaller than the prepared samples in the presence of BAK Figs. 4-6, respectively.

Although SEM is not an accurate technique to determine the particle size, according to particle size distributions of $\mathrm{ZnO}$ nanoparticles based on SEM images, $\mathrm{ZnO}$ particles without surfactant reveal an average size of $86 \mathrm{~nm}$, as shown in Fig. 7. However, the results for $\mathrm{ZnO}$ samples with BAK revealed a bigger average size of $125 \mathrm{~nm}$ for $\mathrm{ZnO}$ with BAK below CMC point, $145 \mathrm{~nm}$ for $\mathrm{ZnO}$ with BAK at CMC point, and $212 \mathrm{~nm}$ for $\mathrm{ZnO}$ with $\mathrm{BAK}$ above CMC point. These samples are not nanosized, as shown in Figs. 8-10. The actual reason is due to BAK's bulky structure which contains 25 carbon atoms in the tail that cause the agglomeration; as a result of this led to an increase in the size of the particles [9]. 


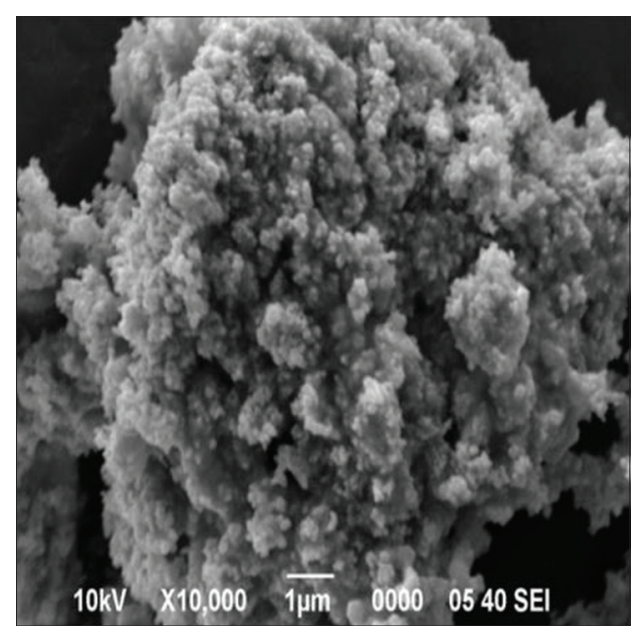

Fig. 3. SEM analysis of $\mathrm{ZnO}$ without surfactant.

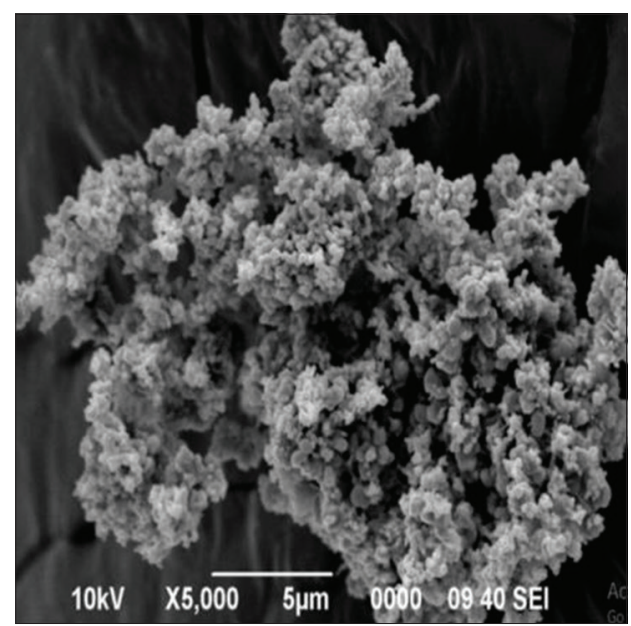

Fig. 4. SEM analysis of $\mathrm{ZnO}$ with benzalkonium chloride surfactant below critical micelle concentration.

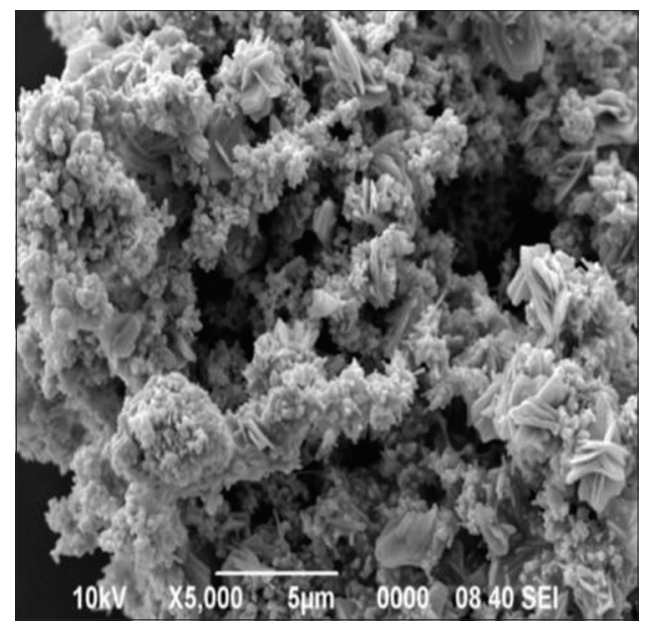

Fig. 5. SEM analysis of $\mathrm{ZnO}$ with benzalkonium chloride surfactant at critical micelle concentration.

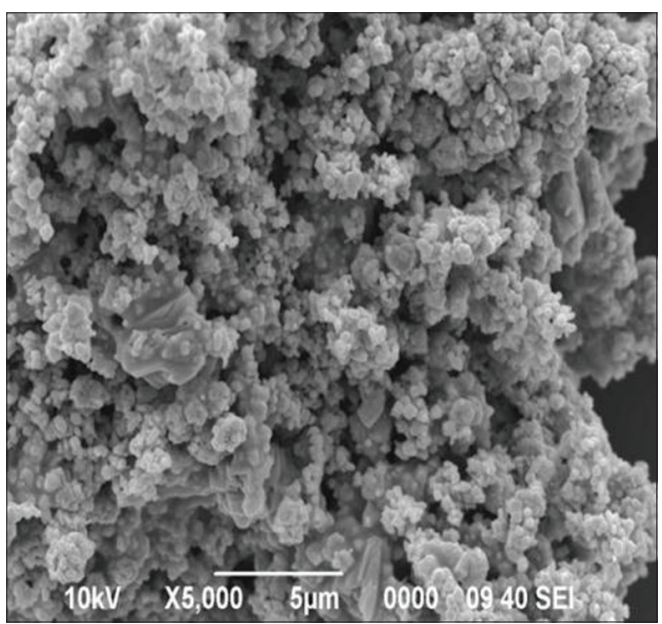

Fig. 6. SEM analysis of $\mathrm{ZnO}$ with benzalkonium chloride surfactant above critical micelle concentration.

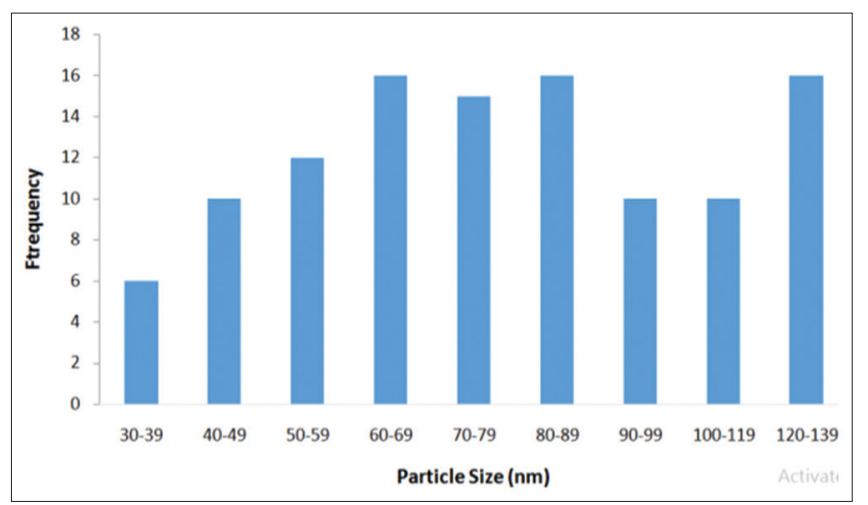

Fig. 7. The particle size distribution of $\mathrm{ZnO}$ without surfactant.

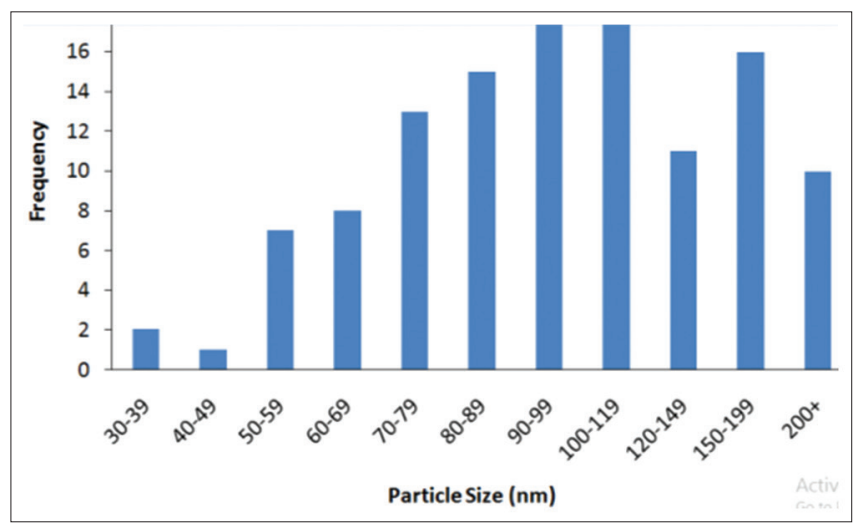

Fig. 8. The particle size distribution of $\mathrm{ZnO}$ with benzalkonium chloride surfactant below critical micelle concentration.

\subsection{Analysis of Ultraviolet-Visible Near Infrared (UV- Vis-NIR) Spectroscopy}

Figs. 11-14 illustrate the $\alpha \mathrm{h}^{2}$ versus hu plot used for the estimation of the bandgap of $\mathrm{ZnO}$ nanoparticles calcined

UHD Journal of Science and Technology | Jan 2020 | Vol 4 | Issue 1 


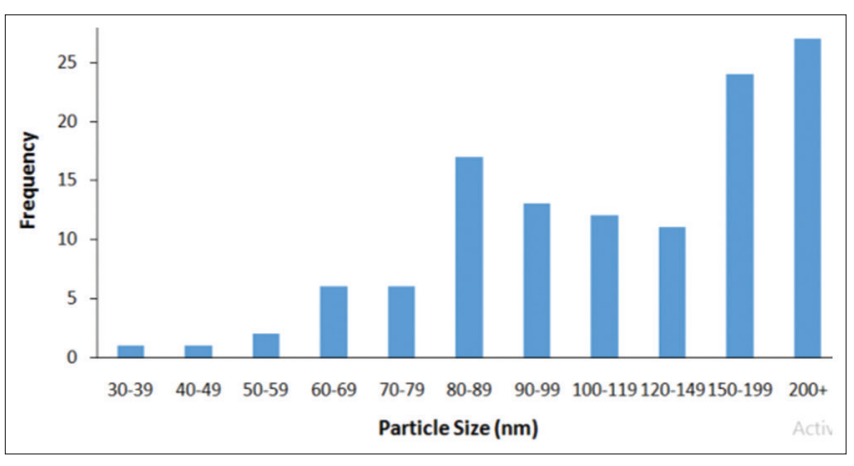

Fig. 9. The particle size distribution of $\mathrm{ZnO}$ with benzalkonium chloride surfactant at critical micelle concentration.

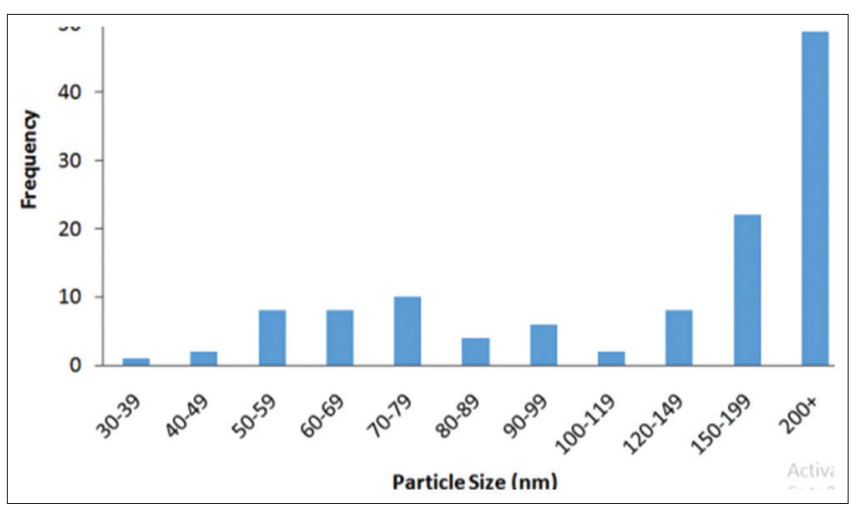

Fig. 10. The particle size distribution of $\mathrm{ZnO}$ with benzalkonium chloride surfactant above critical micelle concentration.

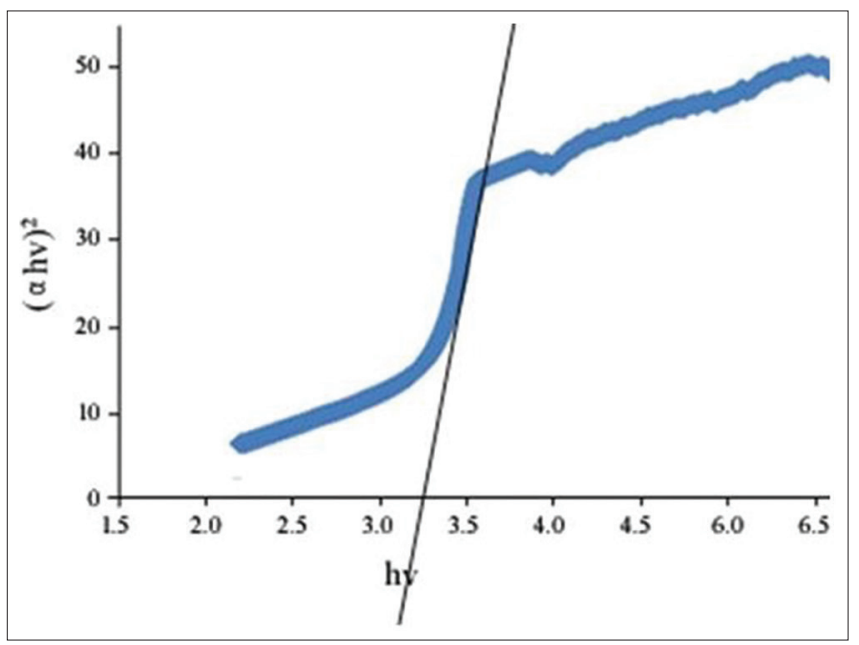

Fig. 11. Analysis of (UVVis-NIR) Spectroscopy of ZnO without surfactant.

at $550^{\circ} \mathrm{C}$ by extrapolating the graph to $\mathrm{X}$-axis so as to calculate the bandgap of the samples. The bandgap is found to be $3.26 \mathrm{eV}, 3.27 \mathrm{eV}, 3.24 \mathrm{eV}$, and $3.21 \mathrm{eV}$ for the samples prepared without surfactant and BAK individually at different concentrations (below, at, and after), respectively.

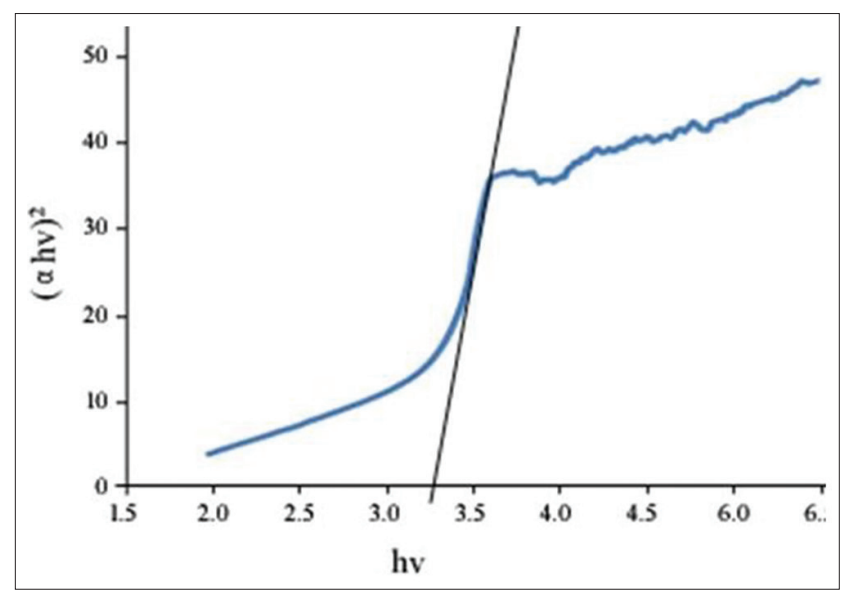

Fig. 12. Analysis of (UVVis-NIR) Spectroscopy of ZnO with benzalkonium chloride below critical micelle concentration.

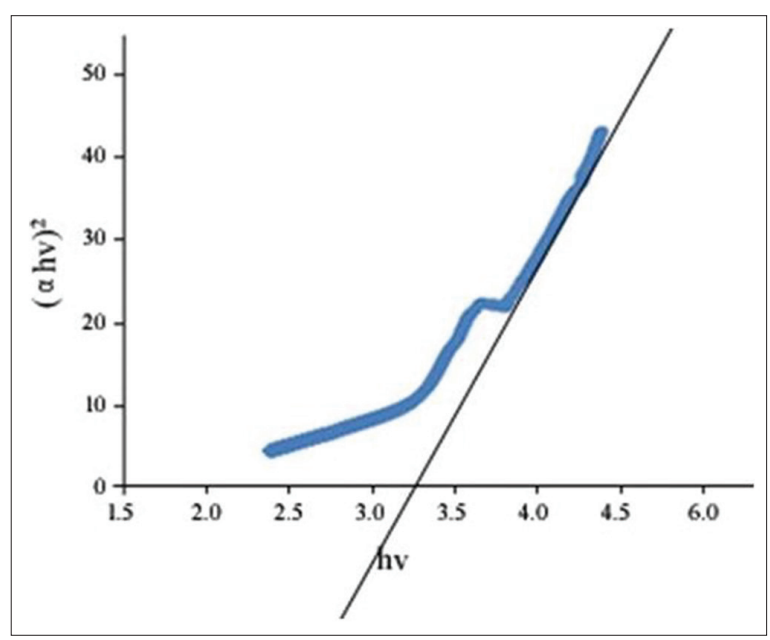

Fig. 13. Analysis of (UVVis-NIR) Spectroscopy of $\mathrm{ZnO}$ with benzalkonium chloride at critical micelle concentration.

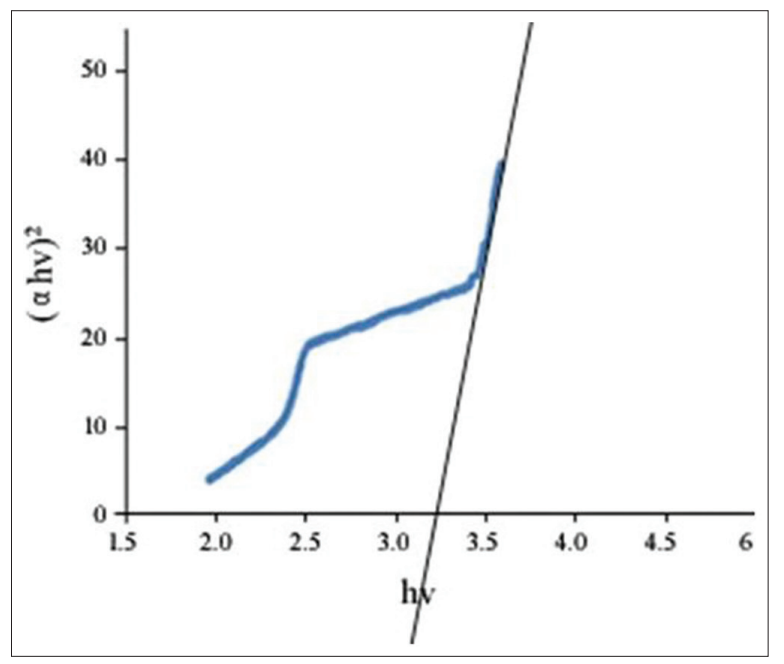

Fig. 14. Analysis of (UVVis-NIR) Spectroscopy of ZnO with benzalkonium chloride above critical micelle concentration. 
The bandgap decreases in the presence of BAK surfactant because of its bulky structure which contains 25 carbon atoms in the tails that cause agglomeration [9]. Although the results show two curves, which apparently means impurities presence.

Table 1 reveals a comparison of bandgap energy for each sample:

\subsection{Analysis of X-ray Diffractometer (XRD)}

Fig. 15 shows the XRD patterns of the $\mathrm{ZnO}$ nanoparticles calcined at $450^{\circ} \mathrm{C}$ for $2 \mathrm{~h}$. A study of standard data JCPDS 760704 confirms that all the synthesized materials are hexagonal $\mathrm{ZnO}$ phase (wurtzite structure). The XRD pattern for the $\mathrm{ZnO}$ nanoparticle prepared without surfactant calcined at $450^{\circ} \mathrm{C}$ for $2 \mathrm{~h}$ is shown in Fig. 15. The three highest spectrums were assigned as 100, 002, and 101 matched planes for $2 \Theta$ values of $31.769,34.422$, and $36.254^{\circ}$, respectively. The calculated average size of the most intense three diffraction spectrums was $76.9 \mathrm{~nm}$.

The XRD pattern of the $\mathrm{ZnO}$ nanoparticle prepared with BAK surfactant below CMC calcined at $550^{\circ} \mathrm{C}$ for $5 \mathrm{~h}$ is shown in Fig. 16. The three highest spectrums were assigned

\section{TABLE 1: Bandgap energy for each sample.}

\begin{tabular}{lc}
\hline Status & Bandgap for ZnO: Benzalkonium chloride \\
\hline Below CMC & $3.27 \mathrm{eV}$ \\
At CMC & $3.24 \mathrm{eV}$ \\
Above CMC & $3.21 \mathrm{eV}$ \\
\hline
\end{tabular}

CMC: Critical micelle concentration, ZnO: Zinc oxide as (100), (002), and (101) matched planes for $2 \Theta$ values of $31.769,34.422$, and $36.254^{\circ}$, respectively. The structure of synthesized material is hexagonal $\mathrm{ZnO}$ (wurtzite structure), according to standard data JCPDS 76-0704. The calculated average size of the most intense three diffraction spectrums was $116.4 \mathrm{~nm}$. Moreover, the structure was hexagonal as the others. On the other hand, Fig. 17 shows the XRD pattern of the $\mathrm{ZnO}$ nanoparticle prepared with BAK surfactant at $\mathrm{CMC}$ calcined at $550^{\circ} \mathrm{C}$ for $5 \mathrm{~h}$. The three highest spectrums were assigned as (100), (002), and (101) matched planes for $2 \Theta$ values of $31.769,34.422$, and $36.254^{\circ}$, respectively. The calculated average size of the most intense three diffraction spectrums was $130.0 \mathrm{~nm}$.

The XRD pattern for the $\mathrm{ZnO}$ nanoparticle prepared with BAK surfactant above $\mathrm{CMC}$ calcined at $550^{\circ} \mathrm{C}$ for $5 \mathrm{~h}$ is shown in Fig. 18. The three highest spectrums were assigned as (100), (002), and (101) matched planes for $2 \Theta$ values of $31.769,34.422$, and $36.254^{\circ}$, respectively. The calculated average size of the most intense three diffraction spectrums was $240.0 \mathrm{~nm}$. As its obvious, the particle size of $\mathrm{ZnO}$ samples in the presence of BAK increased due to the bulky and hydrophobic bi-tailed structure of BAK. The tail of BAK contains 25 carbon atoms, which cause agglomeration and lead to increase in the particle size [9].

\subsection{Analysis of Transmission Electron Microscopy (TEM)}

TEM was used to determine the average particle size. The results that obtained by TEM image and TEM particle

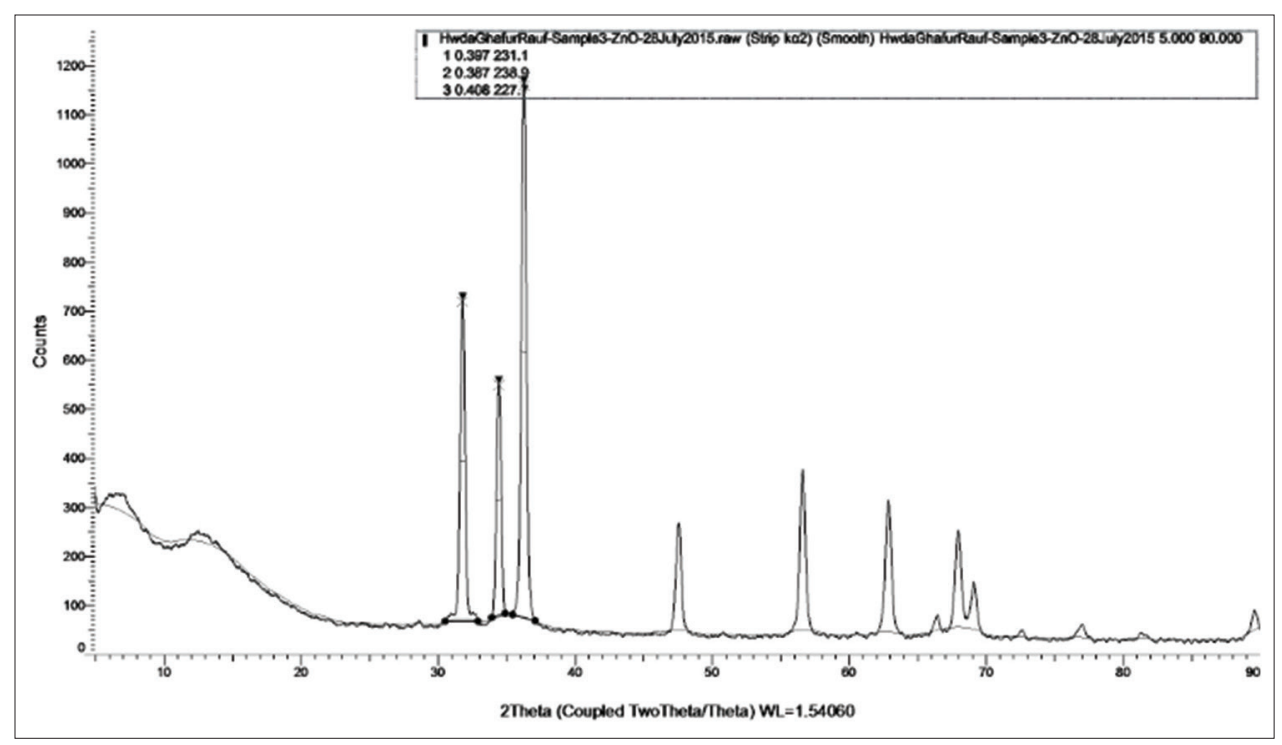

Fig. 15. XRD diffractogram of zinc oxide nanoparticles without surfactant. 


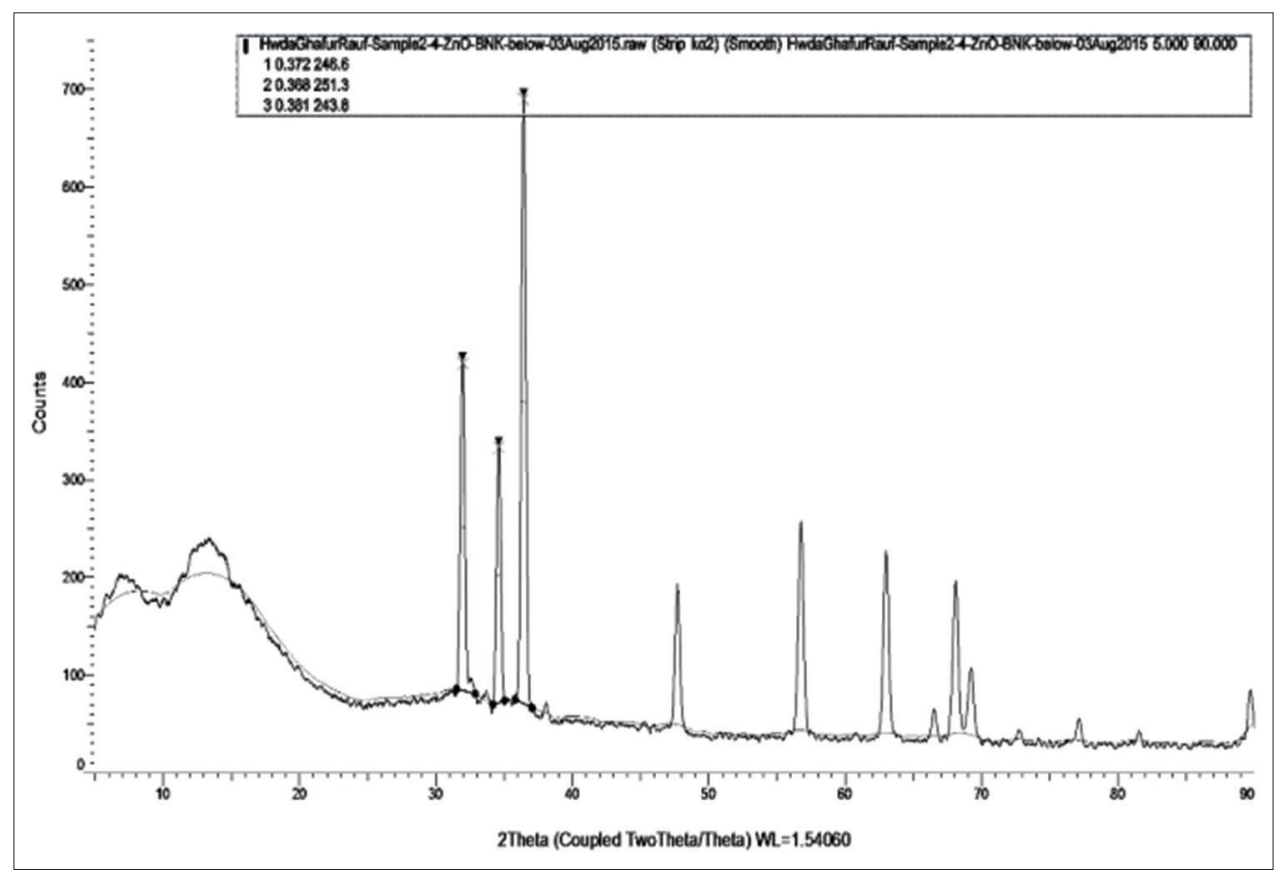

Fig. 16. XRD diffractogram of zinc oxide nanoparticles with benzalkonium chloride Surfactant below critical micelle concentration.

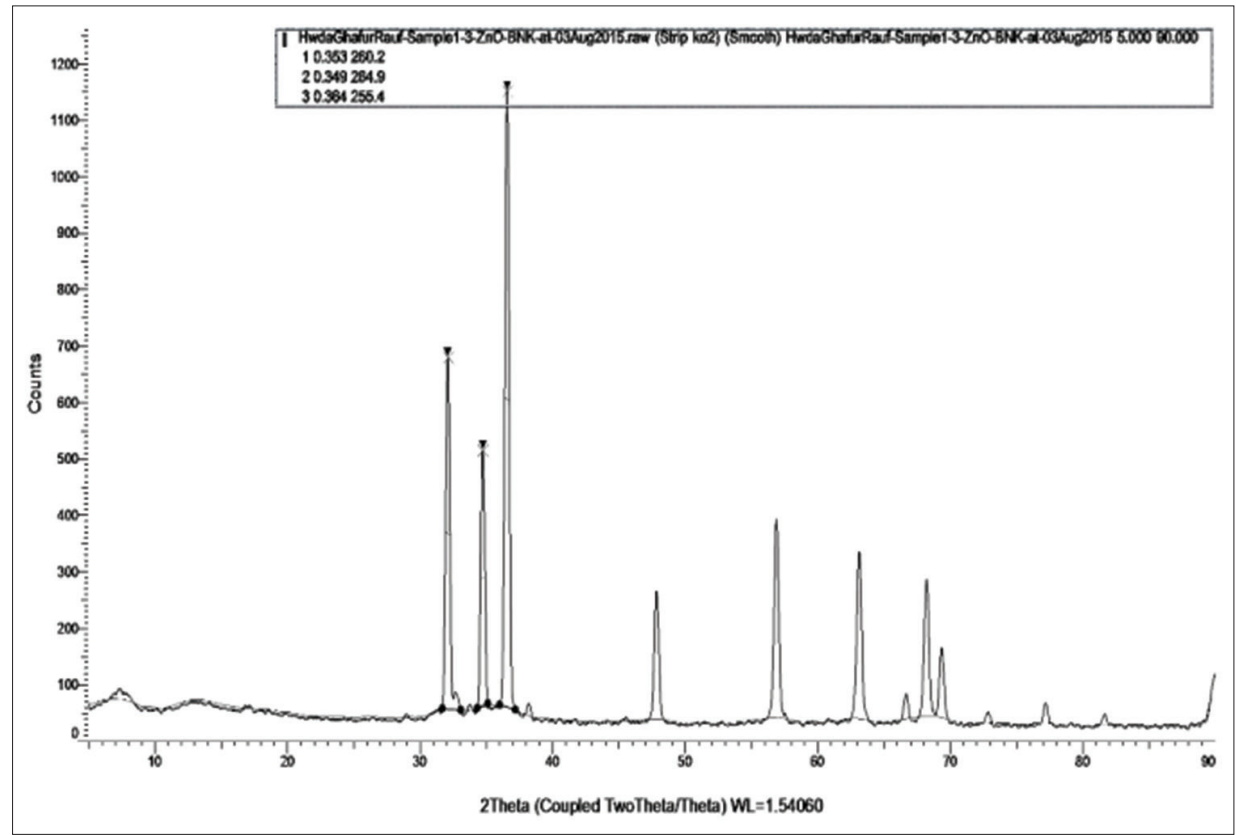

Fig. 17. XRD diffractogram of zinc oxide nanoparticles with benzalkonium chloride surfactant at critical micelle concentration.

size distribution of the $\mathrm{ZnO}$ sample without surfactant were $66 \mathrm{~nm}, 100 \mathrm{~nm}$ for $\mathrm{ZnO}$ with BAK below CMC, and $140 \mathrm{~nm}$ for $\mathrm{ZnO}$ with BAK at CMC, as shown in Figs. 1924 , respectively. As it is been mentioned in the previous investigations, the particle size of $\mathrm{ZnO}$ samples in the presence of BAK increased due to the bulky and bi-tailed structure of BAK. The tail of BAK contains 25 carbon atoms, which causes agglomeration and lead to an increase in the particle size [9].

The calculated particle sizes for each sample from XRD, TEM, and SEM are depicted in Table 2. 


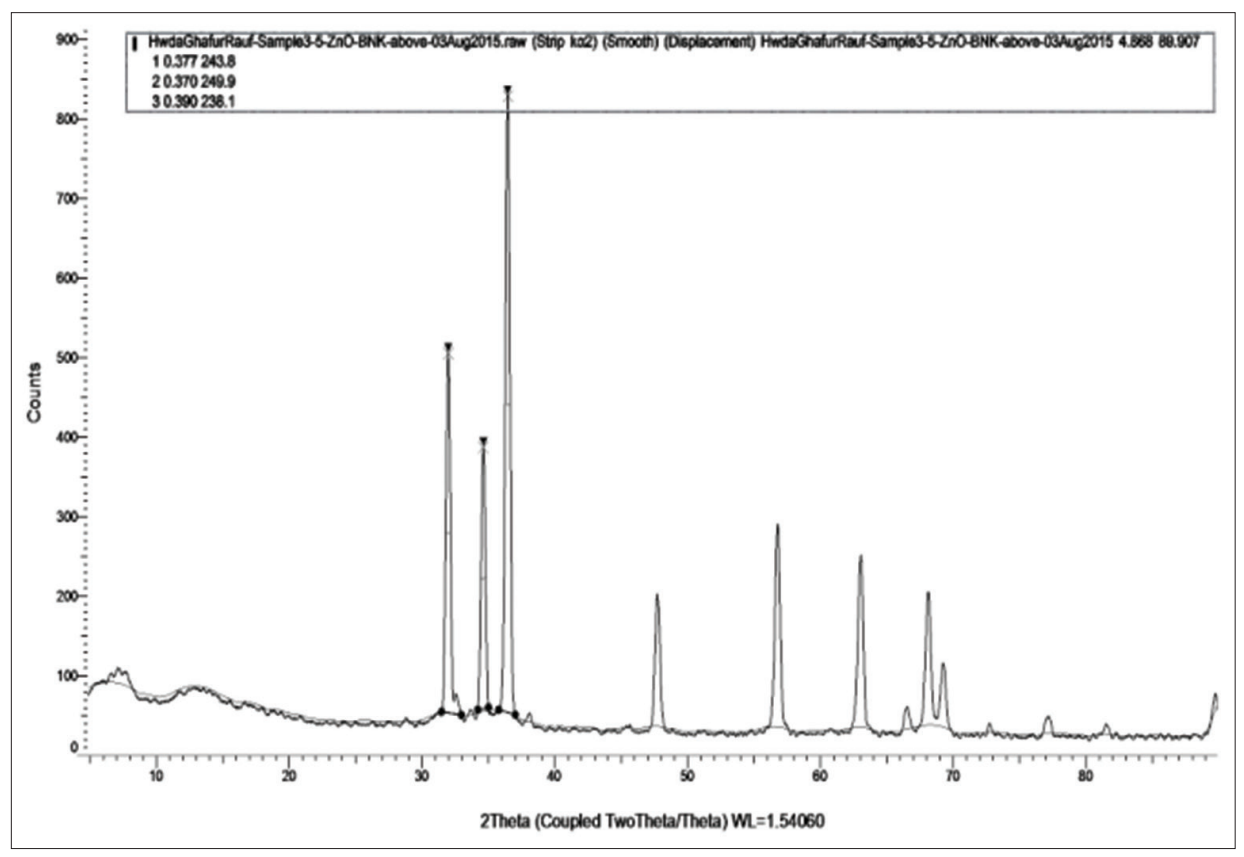

Fig. 18. XRD diffractogram of zinc oxide nanoparticles with benzalkonium chloride surfactant above critical micelle concentration.

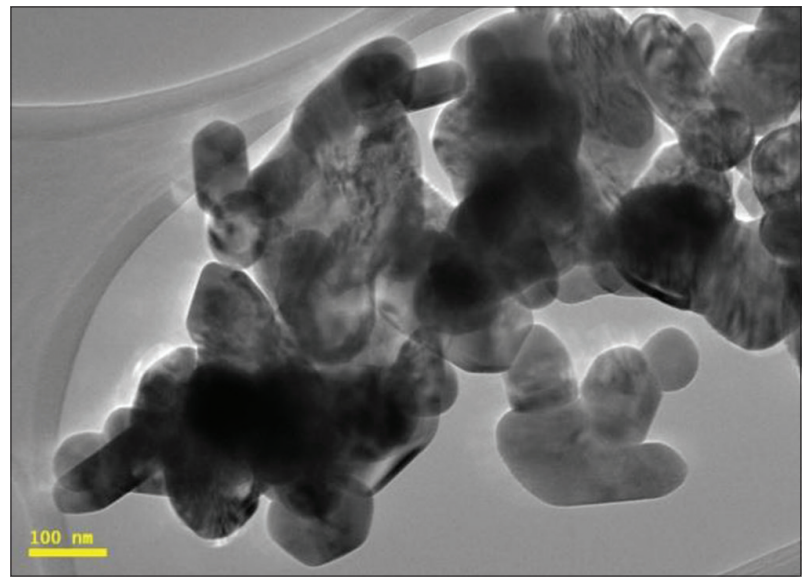

Fig. 19. TEM analysis of $\mathrm{ZnO}$ without surfactant.

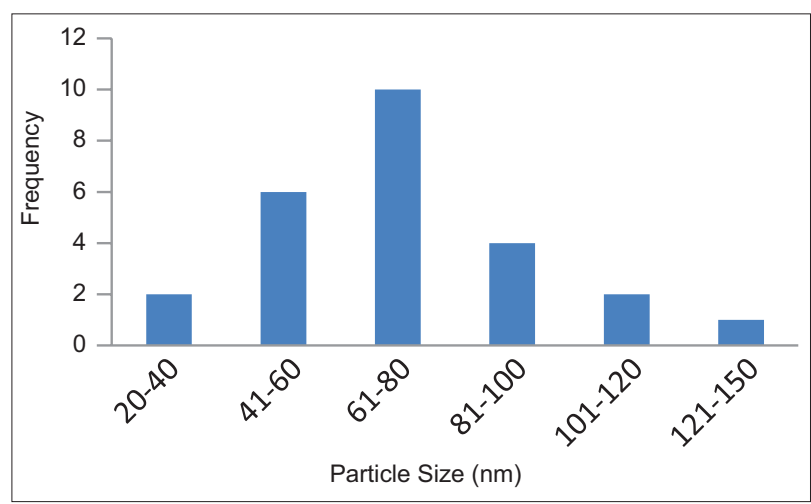

Fig. 20. Particle size distribution of $\mathrm{ZnO}$ based on TEM without surfactant.

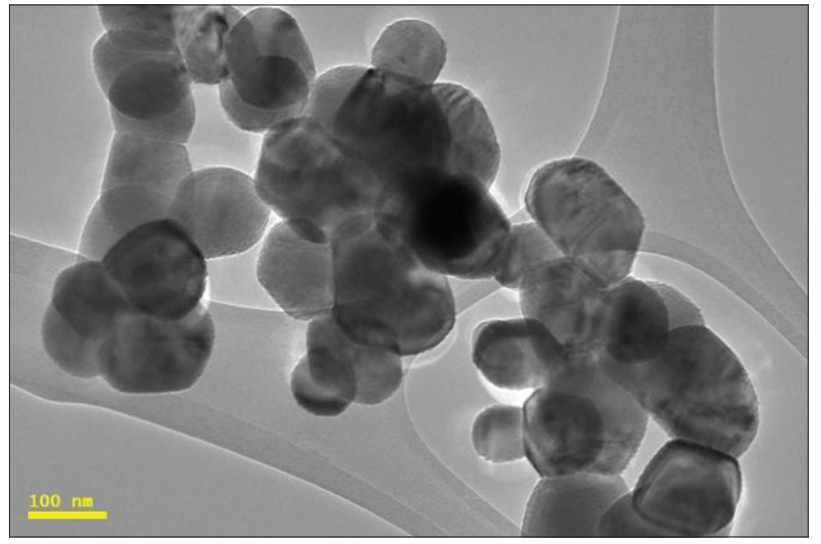

Fig. 21. TEM analysis of $\mathrm{ZnO}$ with benzalkonium chloride below critical micelle concentration.

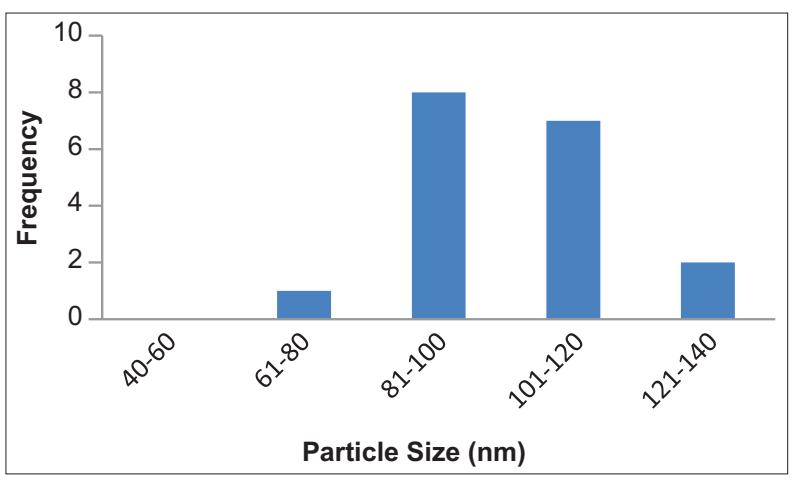

Fig. 22. Particle size distribution of $\mathrm{ZnO}$ based on TEM with benzalkonium chloride below critical micelle concentration.

UHD Journal of Science and Technology | Jan 2020 | Vol 4 | Issue 1 
TABLE 2: Calculated particle sizes for each sample from XRD, TEM, and SEM in different conditions.

\begin{tabular}{lcccc}
\hline Status & Temperature ${ }^{\circ} \mathbf{C}$ & $\begin{array}{c}\text { Average particle size } \\
\text { from XRD } \mathbf{~ n m}\end{array}$ & $\begin{array}{c}\text { Average particle } \\
\text { size from TEM } \mathbf{n m}\end{array}$ & $\begin{array}{c}\text { Average particle size } \\
\text { from SEM } \mathbf{~ n m ~}\end{array}$ \\
\hline ZnO without surfactant & 500 & 76.9 & 66 & 100 \\
ZnO with BAK below CMC & 500 & 116.4 & 140 & 125 \\
ZnO with BAK at CMC & 500 & 130 & - & 145 \\
ZnO with BAK above CMC & 500 & 240 & & 212 \\
BAK & & & & \\
\hline BAK: Benzalkonium chloride, ZnO: Zinc oxide, CMC: Critical micelle concentration, TEM:Transmission electron microscopy, SEM:Scanning electron microscope
\end{tabular}

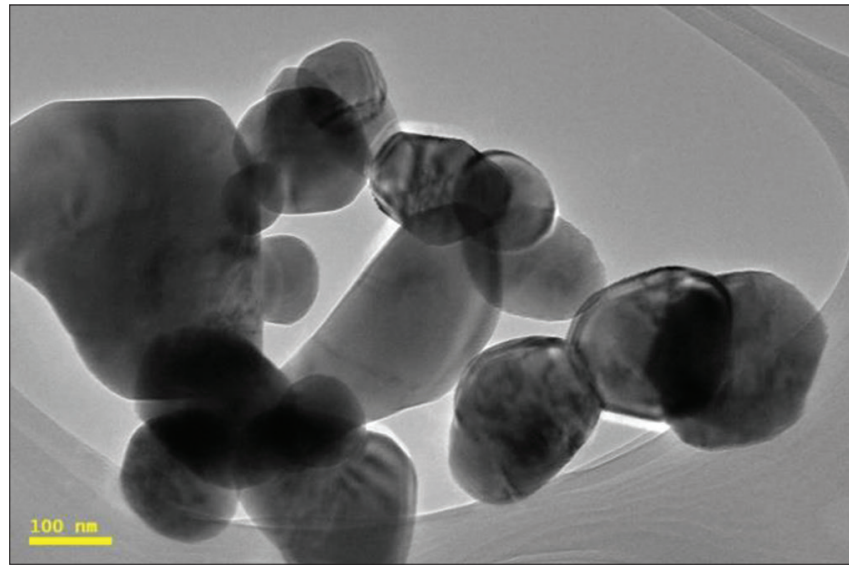

Fig. 23. TEM analysis of $\mathrm{ZnO}$ with benzalkonium chloride at critical micelle concentration.

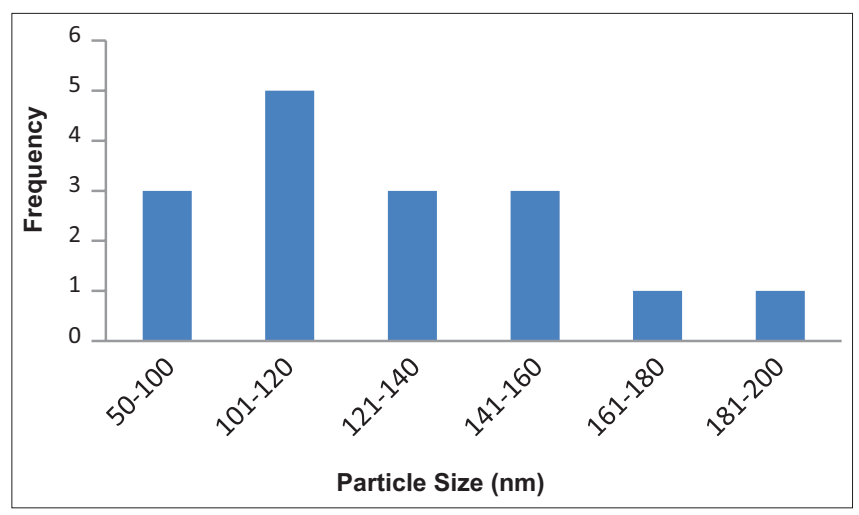

Fig. 24. Particle size distribution of $\mathrm{ZnO}$ based on TEM with benzalkonium chloride at critical micelle concentration.

\section{CONCLUSION}

In this paper, sol-gel method was used to synthesize $\mathrm{ZnO}$ with controllable particles. Afterward, three samples of $\mathrm{ZnO}$ nanoparticles were synthesized with and without surfactant, to study the influence of BAK as cationic surfactants on properties of $\mathrm{ZnO}$ nanoparticles such as particle size, morphology, and bandgap energy [2]. Although this agglomeration can be counted on to prevent toxicity of nanoparticles, especially in cosmetic products as zinc oxide is widely used such as sunscreen or industrial factories like paint factories [3]. Nanoparticles recently conceded to be dangerous, both medically and environmentally [4]. In fact, It has the ability to make the particles very reactive or catalytic because it has a high surface [5]. They are also capable of harming cell membranes in organisms and biological systems [6]. However, if the particles are larger in size, they are unlikely to harm the cell nucleus and other internal cellular components due to the particle agglomeration [7].

Lung inflammatory and systemic activity can be noticed in experimental animals when they inhaled ultrafine particles unlike an equal mass of larger particles, which they may also affect adult human subjects [8].

TEM, SEM, FTIR spectroscopy, X-ray diffraction (XRD), and UV-visible spectroscopy were used to characterize the structure, morphology, and size of the synthesized $\mathrm{ZnO}$ nanoparticles. The surfactants create their own interface and form micelles at CMC [13]. Under these conditions, there would be micelle formation in the bulk phase and surfactant-coated nanoparticles formed start to decrease by increasing surfactant concentration beyond the CMC point [14].

Moreover, with the addition of BAK surfactant, the particle size of all the samples starts to increase due to the bulky hydrophobic part and carbon number in the structure of BAK which is for both tails is 25 , which causes agglomeration [9].

The XRD patterns of the $\mathrm{ZnO}$ nanoparticles; based on the study of standard data JCPDS 76-0704 confirm that all the samples of synthesized $\mathrm{ZnO}$ are hexagonal (wurtzite structure). On the other hand, UV-Vis-NIR result revealed that the bandgap value for $\mathrm{ZnO}$ without any surfactant was $3.26 \mathrm{eV}$ while with $\mathrm{BAK}$ at the same point was $3.24 \mathrm{eV}$. 


\section{ACKNOWLEDGMENTS}

The authors are thankful to Prof. Madzlan University Technology Malaysia for his review and guidance.

\section{FUNDING}

This work is not funded by anyone.

\section{COMPETING INTEREST}

The authors declare that they have no competing interest.

\section{REFERENCES}

[1] E. A. Meulenkamp. "Synthesis and growth of $\mathrm{ZnO}$ nanoparticles". The Journal of Physical Chemistry B, vol. 102, no. 29, pp. 55665572, 1998.

[2] D. Li and R. B. Kaner. "Shape and aggregation control of nanoparticles". Journal of the American Chemical Society, vol. 128, no. 3, pp. 968-975, 2006.

[3] M. J. Osmond and M. J. McCall. "Zinc oxide nanoparticles in modern sunscreens: an analysis of potential exposure and hazard". Nanotoxicology, vol. 4, no. 1, pp. 15-41, 2010.

[4] M. A. Zoroddu, S. Medici, A. Ledda, V. M. Nurchi, J. Lachowicz and M. Peana. "Toxicity of nanoparticles". Current Medicinal Chemistry, vol. 21, no. 33, pp. 3837-3853, 2014.

[5] Y. Jackie. Nanostructured Materials. Academic Press, New York, 2001.

[6] M. W. Frampton. "Systemic and cardiovascular effects of airway injury and inflammation: Ultrafine particle exposure in humans". Environmental Health Perspectives, vol. 109, pp. 529-532, 2001.

[7] C. Greulich, J. Diendorf, T. Simon, G. Eggeler, M. Epple and M. Köller. "Uptake and intracellular distribution of silver nanopahrticles in human mesenchymal stem cells". Acta Biomaterialia, vol. 7, no. 1, pp. 347-354, 2011.

[8] G. Oberdörster, J. Ferin, S. Soderholm, R. Gelein, C. Cox, R. Baggs and P. Morrow. "Increased pulmonary toxicity of inhaled ultrafine particles". Annals of Occupational Hygiene, vol. 38, pp. 295-302, 1994.

[9] R. Mandavi, R., K. S. Santosh and N. Rathore. "Critical micelle concentration of surfactant, mixed surfactant and polymer by different method at room temperature and its importance". Oriental Journal of Chemistry, vol. 24, no. 2. pp. 559-564, 2008.

[10] M. Gusatti, G. Barroso, J. Rosário and C. E. Campos. "Synthesis of $\mathrm{ZnO}$ nanostructures in low reaction temperature". Chemical Engineering Transactions, vol. 17, pp. 1017-1021, 2009.

[11] D. J. Sornalatha and P. Murugakoothan. "Room temperature synthesis of $\mathrm{ZnO}$ nanostructures using CTAB assisted sol-gel method for application in solar cells". International Journal of Emerging Technology and Advanced Engineering, vol. 3, no. 9, pp. 414-418, 2013.

[12] Y. Gargouri, R. Julien, A. Bois, R. Verger and L. Sarda. "Studies on the detergent inhibition of pancreatic lipase activity". Journal of Lipid Research, vol. 24, no. 10, pp. 1336-1342, 1983.

[13] M. A. Farrukh, P. Tan and R. Adnan. "Influence of reaction parameters on the synthesis of surfactant-assisted tin oxide nanoparticles". Turkish Journal of Chemistry, vol. 36, no. 2, pp. 303-314, 2012.

[14] E. Y. Bryleva, N. Vodolazkaya, N. Mchedlov-Petrossyan, L, Samokhina, N. Matveevskaya and A. Tolmachev. "Interfacial properties of cetyltrimethylammonium-coated $\mathrm{SiO}_{2}$ nanoparticles in aqueous media as studied by using different indicator dyes". Journal of Colloid and Interface Science, vol. 316, no. 2, pp. 712722, 2007. 